\title{
DENTAL HEALTH WORK IN MASSACHUSETTS
}

\author{
By EVELYN C. SCHMIDT, Health Instructor in Mouth Hygiene, Massachusetts \\ Department of Public Health, State House, Boston
}

(Read before the American Dental Association, Los Angeles, California, July 17-21, 1922)

$\mathrm{H}^{2}$

ERBERT SPENCER once said in a prophetic moment, "To be a nation of 'good animals' is the first condition to national prosperity." Likewise, the prosperity of a state is measured by the health of its citizens.

It was, therefore, for the purpose of making health an asset in Massachusetts that a State Board of Health was founded 53 years ago, the first in this country. Its aims are the eradication of preventable disease and the maintenance of citizens in the best physical and mental condition.

Dental health work logically comes under both of these headings as dental caries is a preventable disease, the existence of which is detrimental to the health of the individual.

For years dentistry was an isolated, segregated profession. Gradually, however, the close relationship between the health of the oral cavity and the general health of the individual has been recognized by the dental and medical professions. But it is only recently that mouth hygiene, en masse, has begun to receive official attention as an integral part of public health protection and to be co-ordinated with other forms of health work.

As public health work is branching out and its roots are becoming more firmly embedded in the solid foundation of prevention, specialists, obstetricians, pediatricians, nutritionists, industrial physicians, dentists, and educators are developing less exaggerated notions of the importance of their particular field and are joining hands to help people along the highway to good health. The obstetrician is discussing the possible relationship of focal infection of the teeth to the toxemias of pregnancy. The dentist and nutritionist are studying the effects of diet on the teeth. The educator is recognizing the part which mouth hygiene plays in the school room and so on ad finitum.

The staggering problem of dental decay with which the dentist has been confronted for generations is now a public health problem in which all health workers are interested.

Let us review the situation as it is seen from the state house.

Geographically the state presents all types of communities. The little town of Mt. Washington carefully snuggling its 73 inhabitants at the foot of the hills which make it a hard day's trip to the dentist; Boston harboring 750,000 heterogeneous souls, with 1,000 dentists at their beck and call. Still in both places old people are chewing without teeth, school children crying because of their 
teeth, and the family toothbrush still hangs by the sink!

What must be done?

Of course dentists must continue filling the teeth of those who seek their services, but for the multitude who do not, because they cannot, because they will not, or because they do not understand, something must be done.

Is it a state problem? Should the state provide the treatment and educate the people?

The answer in our state is based on a policy that the citizens decided upon and have upheld for years - that of local responsibility and control. Because this is the sentiment of the people, the State Department of Health serves the people merely in an advisory and educational capacity, while the community assumes the responsibility of providing treatment, when it is necessary, either under official or unofficial auspices. In fact, in 1920 a statute was passed empowering cities and towns to establish dental, medical, and health centers and to conduct educational campaigns in connection therewith under the auspices of the board of health.

As communities begin to realize the magnitude of the mouth hygiene problem in their midst, the initial step which they take to counteract this is that which is most spectacular and comprehensible,the reparative dental clinic.

The first dental clinic in Massachusetts for people with limited incomes was established in 1867 coincident with the Harvard Dental School. In 1874 the first dispensary dental clinic was opened. Dental service in the beginning was primarily for adults, but in 1908 a step toward preventive dentistry was taken, for it was then that the first school dental clinic was founded, a clinic primarily for children.

During the fourteen ensuing years dental service for school children has in- creased to the extent that now 138 of the 355 cities and towns or about 38 per cent of the communities in the state have some form of service.

Ninty-three of these communities have their own equipment, meagre in many instances but always a source of civic pride; and, after all, is it not the mental attitude which prevails within a clinic rather than the equipment which makes for success. Of course everyone recognized that an ideally equipped clinic is a psychological asset but it is sometimes an unwarranted extravagance. Sixty-one per cent of these clinics are under official auspices, 39 per cent under unofficial. Some of the clinics operate one day a week, some every school day, the dental clinicians receiving salaries varying from 80 cents to $\$ 4.00$ an hour, the average being $\$ 1.65$. Perhaps it is fitting to mention here that it is hoped that a scale of salaries based on preparation and experience may be worked out by such a body as the American Dental Association. Suggestions as to personal qualification might be apropos, for because a dentist is a dentist he is not necessarily fitted for school work. The dental schools might help to improve this condition by giving special training for this type of service. It is men with patience, vision and understanding that we need.

As I said the state has no mandatory power over the establishment and maintenance of clinics. We act as a clearing house where citizens may come to find what other communities are doing, to get suggestions about equipping and operating a clinic. We also try to interest and stimulate communities to realize the importance of dental health work. Believing that a "dental awakening" as I like to call it, is essential in every town, we have outlined a program and prepared material for this,--an exhibit, literature, slides, motion pictures, and lectures. 
There are several important, fundamental points which we urge a community about to establish dental service to heed,- - to seek the co-operation of all official and unofficial agencies and of all local dentists, to think of a school dental clinic not as a thing per se but as part of the health equipment of a school, its aims and policies to be understood by those who touch the health of the school child. They are advised to operate the clinic on the basic idea of prevention and hence to confine the work to a definite field in the lower grades, making general prophylaxis and hygienic instruction the primary and curative work the secondary consideration; to determine, in fairness to the local dentist, that the patient is worthy of service, if it is a philanthropic clinic; to see that the clinic is open to all school children if it is sup. ported by municipal funds. These are a few of the suggestions which we make.

But to return to clinical service; besides the ninty-three communities having permanent clinics, fourteen either appropriate funds for work for needy children to be done by a local dentist or are reached through a health center.

Thirty-one additional rural towns have the services of a traveling clinic, four of which are operating in the state under unofficial auspices,-the County Farm Bureau in three instances and The American Red Cross in the fourth. These clinics are in no way charity clinics. Instead, they answer the question of inaccessibility to dentists for the policy is to operate preferably in towns where there is no local dentist. They are consequently self-supporting, charging from $\$ 2.50$ to $\$ 3.00$ an hour. They work entirely for children although emergency work is done for anyone.

Massachusetts now has twelve communities in which dental hygienists are employed for school work. In one in- stance a private individual supports the work, in the other nine cases, the local board of health. The dental hygienist is gradually finding her place in the broad field of public health work.

Admirable as the increase in school dental service may be, are we reaching the core of preventive dentistry? Our children may leave school with healthier mouths but are our children coming into school with fewer cavities to be filled by the school dentists? Unfortunately, no. To overcome this we must increase the dental facilities for the preschool child and redouble our attention on the mother during the prenatal period.

But the key word to "prevention" is "education". Even now civilized man is fettered by mythical adages which have been handed down from generation to generation. Superstition, prejudice, ignorance must be counteracted-counteracted by education.

Mother must understand that Johnnie does not inherit "soft" teeth from his father but that the predisposing causes of dental infection may be traced to improper diet during pregnancy and infancy. Mothers must know that children do not need to have the so-called children's diseases and that the development of the teeth is seriously interfered with by all diseases affecting the epithelial structure. Parents should learn that the "little taste" of sweet, given with the best intentions, leads to the cultivation of the mythical "sweet tooth" which is injurious to all of the teeth. People must be aroused to the realization of the importance of the first teeth, of the sixth year molars-of all the cardinal points in dental health.

Dentists alone can never reach all the people with the truth about preventive dentistry. They can, however, teach others who in turn come in contact with the laity from different angles. Because 
of my aspiration for the ideal and my confidence in the future of preventive dentistry I venture to suggest that there should be more emphasis laid on the subject in normal schools for teachers, in training schools for nurses, in training courses for public health nurses, in medical schools and, I am forced to add, in the dental schools also.

Our educational work, as I previously said, is carried on through motion pictures, lectures, slides, charts, mottoes, posters, exhibits, and literature, all of which may be obtained gratuitously by any citizen of the state. In all of our teaching we try to emphasize the positive rather than the negative. "Decayed teeth" is not an euphonious phrase. Therefore, we try to construct healthy mouths with diet (delicious fruits, tasty vegetables, palatable eggs, natural grains) with mastication, refreshing brushing, and frequent visits to the dentist, all factors over which every individual has control. And these mouth hygiene hints appear in our prenatal and postnatal letters, in our literature on infant and child care, on diet, and of course, in all literature on mouth hygiene.

Through joint conferences of the Department of Education and the Department of Public Health which have brought together workers in both fields, teachers, school nurses, school physicians, nutritionists and hygienists, methods for emphasizing the importance of mouth hygiene have been discussed. This year we hope to reach these groups again as well as to give lectures on oral hygiene in the normal schools thus acting as a link between the dentist and the school teacher.

And all the time we are looking for guidance. No matter how many people may be teaching in a simple manner the truth about a clean mouth, in the class room, in clinics, before club women, in industrial plants, everywhere, all are looking to the dentist to tell definitely why teeth decay, how important vitamines are, and if candy really is bad for the teeth.

You know the questions. Dentists must answer them if they are to do their share toward building up a prosperous, healthy nation.

Wise men have taught us to cure evil at its source. Prevention with children is better than cure with adults and so it is for the child that I appeal. Every child has a right to be as healthy as present-day knowledge can make him, but every child does not have a chance. Help him to have it. Help to build up the health of our children. It is a national problem, a state problem, your problem and mine. 